\title{
Does whitebark pine have a refuge from mountain pine beetle at treeline?
}

Colin T. Maher ${ }^{1}$ and Claudine Tobalske ${ }^{2}$

${ }^{1}$ College of Forestry and Conservation, University of Montana

2Montana Natural Heritage Program, Spatial Analysis Lab, University of Montana

Mountain pine beetles are causing historically unprecedented mortality in highelevation whitebark pine. Refuge habitats are one way by which populations may persist through these impacts.

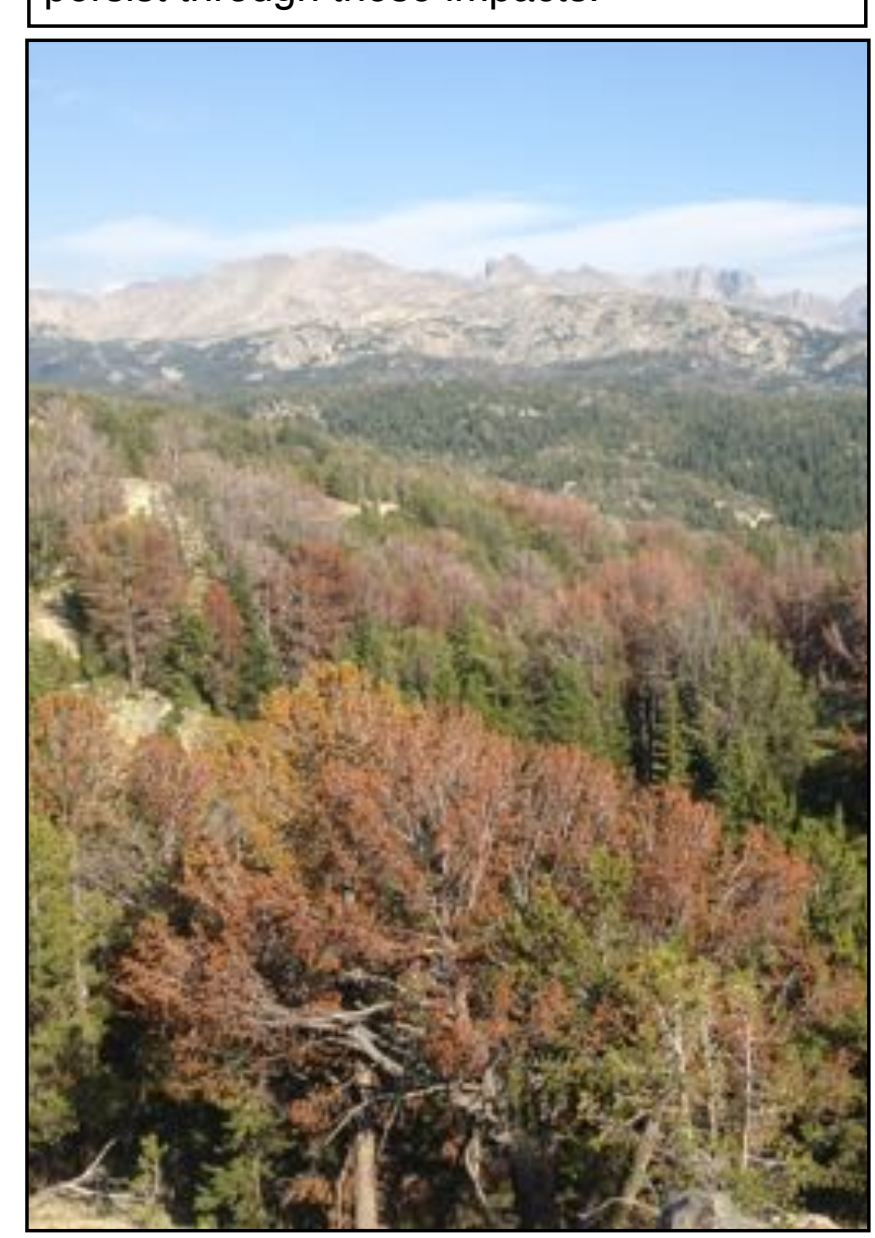

Acknowledgements

The Whitebark Pine Ecosystem Foundation provided travel funding for this study. Thanks also to Wally Macfarlane for sharing an impressive GIS dataset of whitebark mortality in

References

Logan, J. A., W. W. MacFarlane, and L. Willcox. 2010. Ecological Applications 20:895-902. Macfarlane, W. W., J. A. Logan, and W. R. Kern. 2013. Ecological Applications 23:421-437.

\section{FORESTRY\&CONSERVATION}

4
2 Alpine treeline ecotone habitats may be refuges for

2 whitebark pine from MPB attack because treeline growth forms (krummholz) are too small for beetles (Logan et al 2010, Macfarlane et al. 2013).

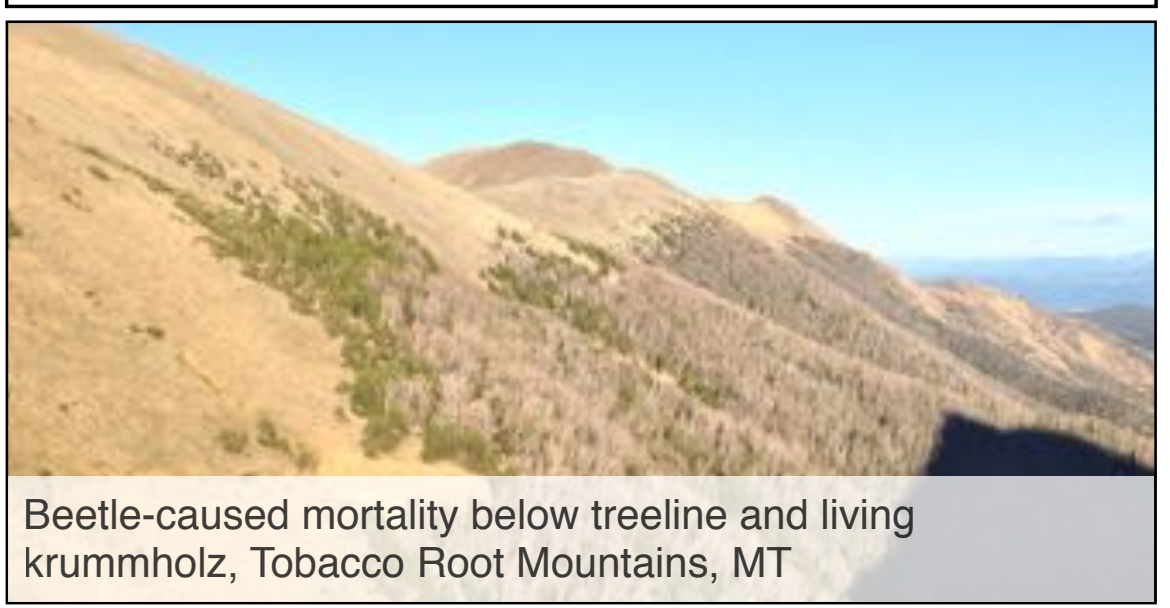

3

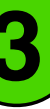

作 cliffs, talus, meadows, lakes, etc.). This is consistent with the hypothesis that treeline habitats are refuges. Treelines may be refuges because of transitions in growth form and because reduced mortality may be common to all forest edges.
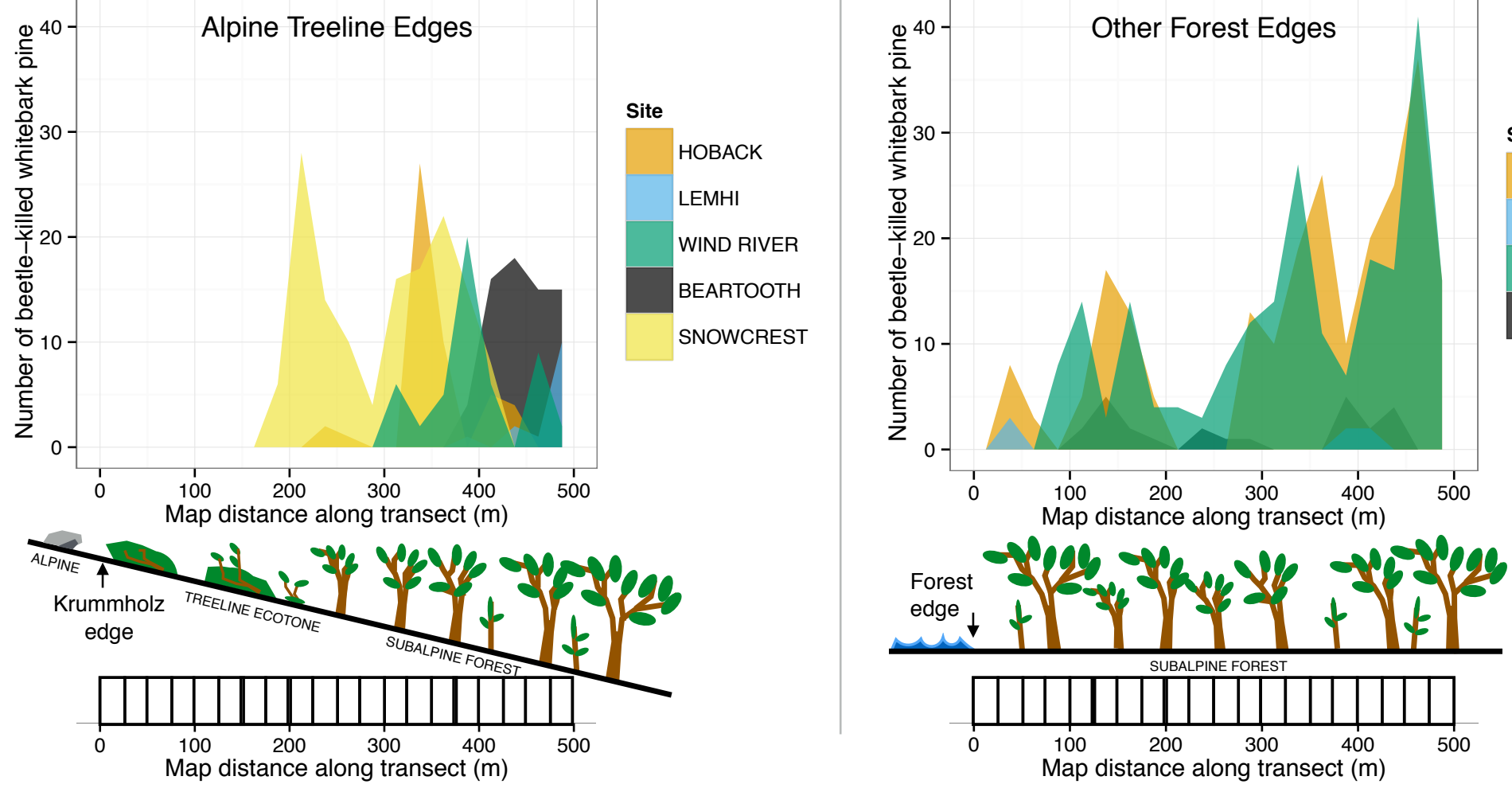